\title{
Age at the onset of tobacco smoking in South Africa: a discrete-time survival analysis of the prognostic factors
}

\author{
Adeniyi Francis Fagbamigbe ${ }^{1,2,3^{*}}$ (D), Rachana Desai ${ }^{4}$, Ronel Sewpaul ${ }^{5}$, Ngianga-Bakwin Kandala ${ }^{6}$, \\ Derrick Sekgala $a^{5}$ and Priscilla Reddy,
}

\begin{abstract}
Background: While knowledge of onset of smoking tobacco, and associated risk factors can aid the formulation of evidence-based policy and interventions, such information is scarce in South Africa. We assessed age at onset of tobacco smoking in South Africa and identified its risk factors.

Methods: We analysed data of 15,316 respondents aged 15-98 years from the 2012 South African National Health and Nutrition Examination Survey. Descriptive statistics and survival analysis techniques were used alongside weighted percentages.

Results: Overall lifetime prevalence of smoking was 20.5\%. Among the 3360 ever-smoked respondents, the overall median age at smoking onset was 18 years (Inter-quartile range $(\mathrm{IQR})=5$ ) with 2\% starting before age 10 while 60\% had smoked before age 20. Likelihood of tobacco smoking was higher among adolescents ( $<=20$ years) and those aged 20-29years than those aged $>=60$ years, thrice higher among males, 29\% higher among urban dwellers and thrice higher in Western Cape and Free State than in North West Province. The onset of tobacco smoking was earlier among males, wealthier and "coloured" people from Northern and Eastern Capes.

Conclusion: The onset of tobacco smoking peaked at 15-22 years and varied by province, sex, location, race and other characteristics. The age restrictions on smoking in South Africa has changed over time, coupled with the recent open and electronic advertisement of tobacco, and social media could have influenced the earlier onset of tobacco smoking in South Africa. Stricter regulations on tobacco-related advertisement and sales should be implemented.
\end{abstract}

Keywords: Tobacco smoking, South Africa, Birth cohorts, Sex, Race, Tobacco advertisement

\section{Background}

Tobacco use is responsible for over 8 million deaths every year and this figure is projected to rise to approximately 10 million deaths per year by 2030 [1] and has been ranked as one of the leading causes of

\footnotetext{
* Correspondence: franstel74@yahoo.com; fadeniyi@cartafrica.org 'Department of Epidemiology and Medical Statistics, College of Medicine, University of Ibadan, Ibadan, Nigeria

${ }^{2}$ Division of Population and Behavioural Sciences, School of Medicine, St Andrews University, Fife, UK

Full list of author information is available at the end of the article
}

preventable deaths globally [2]. According to the WHO, the average global tobacco smoking among populations aged 15 years and older was $21 \%$ [3]. Moreover, South Africans aged 15 years and older reported past month tobacco smoking as high as $31.4 \%$ [4]. Tobacco use is a risk factor to a range of disability and diseases such as lung cancer, stroke, heart disease and chronic respiratory disease $[5,6]$.

An important determinant of smoking behaviours in later life is the age of smoking onset. Research across the

C C The Author(s). 2020 Open Access This article is licensed under a Creative Commons Attribution 4.0 International License, which permits use, sharing, adaptation, distribution and reproduction in any medium or format, as long as you give appropriate credit to the original author(s) and the source, provide a link to the Creative Commons licence, and indicate if changes were made. The images or other third party material in this article are included in the article's Creative Commons licence, unless indicated otherwise in a credit line to the material. If material is not included in the article's Creative Commons licence and your intended use is not permitted by statutory regulation or exceeds the permitted use, you will need to obtain permission directly from the copyright holder. To view a copy of this licence, visit http://creativecommons.org/licenses/by/4.0/ The Creative Commons Public Domain Dedication waiver (http://creativecommons.org/publicdomain/zero/1.0/) applies to the data made available in this article, unless otherwise stated in a credit line to the data. 
globe has shown that the majority of adults initiated tobacco use before the age of 18 [7]. In developing countries, including South Africa, the average age of tobacco initiation was between 12 and 19 years [8-11]. Studies have shown that those who initiate smoking at a young age have greater nicotine dependence than those initiating later $[12,13]$. Early age of smoking onset has furthermore been associated with a likelihood of regular smoking, placing individuals at higher risk for tobaccorelated mortality and morbidity $[9,14]$. If the age of smoking onset continues to decrease, tobacco use will result in the death of 250 million children and young people alive today, many of them in developing countries $[15,16]$. Therefore, a better understanding of the age of when people initiate smoking, as well as when they started smoking is essential to develop more effective prevention efforts and smoking cessation programs for those who are most at risk.

A substantial body of research has identified a broad range of determinants for tobacco use at the individual and the environmental level. Determinants such as demographics (age, gender, race, location), socioeconomic status (SES) (education, occupation and income), psychosocial (norms, attitudes, self-efficacy, knowledge) the social network and policy, have all been linked to the smoking onset and progression $[2,5,7,9,11,12,15-21]$. In a recent study, Morojele et al. found that $44 \%$ of South African adolescents reported lifetime tobacco use. The authors controlled for the adolescents' age, gender, ethnicity and SES in assessing shared and unshared risks of tobacco use among South Africa adolescents, evidence of the significance of these factors [22]. Males have been reported to have a higher prevalence of smoking than the females in South Africa [11]. Also, educational attainment, household wealth quintiles, employment status and location of residence as measures of deprivation have been reported to be associated with smoking [23]. Lau et al. found a significant non-linear association between deprivation and smoking prevalence [23]. The authors reported that the smoking prevalence ratio was highest among those in the middle range but lowest at the uppermost and lowest ends of the deprivation index. Similarly, smoking has been reported to differ by ethnic groups and races in the country. In South Africa, the "coloured" population have been reported to have the highest prevalence of smoking [11, 23, 24].

However, information on the age of smoking onset in low and middle-income countries has been seriously limited by the lack of population-based studies using a standardized methodology [25]. Moreover, research on tobacco use usually report the prevalence of smoking alone, and only a few studies in South Africa provide data on the incidence of smoking onset and factors associated with the timing of the onset. The current study aims to gain an understanding of the age at onset of smoking, the cumulative risk of smoking, and the associated risk factors using a national sample of South African adults.

\section{Materials and methods}

We used the data from the 2012 South African National Health and Nutrition Examination Survey (SANHANES) from individuals aged 15 and older [26].

\section{Study population}

The first round of the SANHANES (SANHANES-1) included a sample of all individuals living in South Africa. All persons living in occupied households were eligible to participate. It excluded individuals staying in educational institutions, old-age homes, hospitals, homeless people, and uniformed-service barracks.

\section{Study design}

The SANHANES-1 obtained questionnaire-based data through interviews in combination with health measurements obtained through clinical examination, a selection of clinical tests as well as the collection of a blood sample. Questions on tobacco use behaviours were administered to individuals aged $>=15$ years. SANHANES- 1 was a cross-sectional survey providing baseline data for future longitudinal analysis.

\section{Sampling}

The survey applied a multi-stage disproportionate, stratified cluster sampling approach. A master sample of 1000 census enumeration areas (EAs) from the 2001 population census from a database of 86,000 EAs was mapped in 2007 using aerial photography. The selection of EAs was stratified by province and locality type. In the formal urban areas, the race was also used as a third stratification variable (based on the predominant race group in the selected EA at the time of the 2001 census). The allocation of EAs to different stratification categories was disproportionate. Based on the Human Sciences Research Council (HSRC) 2007 Master Sample, 500 EAs representative of the socio-demographic profile of South Africa were identified and a random sample of 20 visiting points was randomly selected from each EA, yielding an overall sample of 10,000 households. All members within a sampled household were eligible to participate. The final sample consisted of 8166 valid households, with 27,580 eligible individuals. A total of 25,532 (92.6\%) individuals participated in one or more of the interviews, physical examination and clinical examination, of which 15,316 were aged 15 years or older and answered tobacco-use related questions. Further details on sample procedures are described in Shisana et al. [26]. 


\section{Variables}

The outcome variable is the age of onset of tobacco smoking (TS). Respondents were asked if they have ever smoked tobacco. Those who answered in affirmative were then asked the age when they started smoking or using tobacco. The independent variables, selected based on existing literature $[2,5,7,9,12,15-21]$ are age groups $(<20,20-29,30-39,40-49,50-59$ and $>=60)$, Sex (Male, Female), Location (Rural, Urban), Educational Attainment (No formal education, Grade 8-12, Higher education), Province (Western Cape, Eastern Cape, Northern Cape, Free State, KwaZulu Natal, North West, Gauteng, Mpumalanga, Limpopo), Race (African, White, "Coloured", Indian and Other), Nationality (South African Citizen, Non - Citizen (Permanent Residence), Non-Citizen (Refugee) and Others), Marital Status (Never Married, Currently Married and Formerly Married), Employment Status (Unemployed, Employed) and Wealth Quintile (poorest, poorer, middle, richer and richest). These variables have been identified in previous studies to be associated with tobacco smoking.

\section{Statistical analysis}

The analytic sample consisted of 15,316 individuals aged 15 years and older who responded to questions on tobacco use as sensitive questions such as tobacco-use were only asked from respondents of that age group. Descriptive statistics and survival analysis techniques were used to analyse the data. Percentages were weighted using sampling weights. Kaplan Meier estimates were generated to describe time to the onset of smoking using survival functions. Log-rank tests were used to test the equality of survival curves at $5 \%$ significance level. In the multivariate analysis, a survival analysis regression model was used to model the age at the onset of TS among the studied population. A survival regression model is used in follow-up studies to determine prognostic factors of the timing of an event of interest which is the age at the onset of TS in this study. These models work by combining two variables as the dependent variable. The two variables are (i) censoring indicator (ever smoked and never smoked in the current study) and (ii) survival time (measured as the age at the onset of smoking for the ever-smoked individuals and as the current age as of the date of data collection for the never-smoked individuals). We used the Cox proportional hazard model, one of the survival regression models, to determine the independent variables that predicted the age at the onset of TS in South Africa. The Cox models are based on the assumption of the proportionality of the hazards. The validity of this assumption was assessed using the log-log transformation of the Kaplan-Meier survival curves. The variables that were significant at $p=0.10$ in the bivariate Cox regression models were identified as candidates and added to the multiple Cox regression model to assess their contribution to the timings controlling for confounders. Hazard ratios and their associated 95\% confidence intervals from the Cox regression analysis were evaluated to determine the association of the risk factors with the timing of the onset of tobacco use. The outcomes of the model are the hazard ratios and their associated 95\% confidence intervals. The significance of the HRs was determined using a 95\% confidence interval and Wald's $\chi^{2}$ statistics. We verified whether the proportional-hazards assumption was violated or not across all levels of respondent characteristics. Data were weighted to adjust for unequal population sizes across the EAs and the provinces. All analysis was conducted using Stata version 14 (StataCorp, Texas, USA 2016).

The population at risk in this study comprised every individual involved in the study since any person can start smoking at any point in their lifetime. The duration from the date of birth to age at the onset of tobacco smoking, ' $\mathrm{T}$ ', is assumed to be a discrete random variable that is always positive. The observation continues from birth until time ' $t$ ', at which the event of interest (age at the onset of TS) occurs. The study ends for an individual at a time ' $\mathrm{T}=\mathrm{t}$ ' if he/she started smoking, else such an individual is "censored" as at the survey date. We computed the survival time as the age at onset of smoking for those who had ever smoked or started on the survey day while, for those who have never smoked, the survival time is their age on the survey date. The censoring index for the ever-smoked respondents is " 1 " while it is " 0 " for those who have never smoked. We accounted for the time-varying effects of the age of the respondents, household wealth quintile and educational attainment on the timing of smoking onset among the respondents.

\section{Results}

Among the 15,316 respondents, 22.9\% were aged 19 years or less while $8.7 \%$ were 60 years or more. Also, $54.2 \%$ were females, $63.6 \%$ lived in urban areas, $24.5 \%$ from Gauteng and $2.3 \%$ from North Cape province, $77.9 \%$ are Africans while $10.1 \%$ classified themselves as White, as seen in Table 1. Overall, the lifetime prevalence of smoking, that is, having ever smoked tobacco, in this population was $20.5 \%$. The lifetime prevalence of smoking (10.7\%) was lowest among those aged 19 years or less, while those aged 50 to 59 years had the highest lifetime prevalence (29.2\%). The prevalence was also high among males (33.2\%), and those who classified themselves as coloured (45.9\%). In terms of location, formal urban and rural areas reported lifetime rates of 23. 7 and $25.6 \%$ respectively. The Western Cape (37.9\%) reported the highest lifetime prevalence of smoking, followed by the Northern Cape (33.2\%) and Free State 
Table 1 Distribution of respondents and the lifetime prevalence of tobacco smoking

\begin{tabular}{|c|c|c|c|}
\hline Characteristics & $\%$ & $n=15,316$ & $\begin{array}{l}\text { Lifetime prevalence of smoking } \\
\%(95 \% \mathrm{Cl})\end{array}$ \\
\hline \multicolumn{4}{|l|}{ Age in years } \\
\hline$<20$ & 23.6 & 3607 & $10.7[9.0-12.5]$ \\
\hline $20-29$ & 21.3 & 3258 & 21.0 [18.9-23.3] \\
\hline $30-39$ & 16.4 & 2506 & $23.8[21.4-26.4]$ \\
\hline $40-49$ & 15.4 & 2366 & 27.2 [24.7-29.9] \\
\hline $50-59$ & 12.2 & 1870 & $29.2[26.1-32.4]$ \\
\hline$>=60$ & 11.2 & 1709 & $20.1[16.5-24.1]$ \\
\hline \multicolumn{4}{|l|}{ Sex } \\
\hline Males & 41.6 & 6337 & $33.2[31.1-35.5]$ \\
\hline Females & 58.4 & 8897 & 10.2 [8.9-11.7] \\
\hline \multicolumn{4}{|l|}{ Location } \\
\hline Rural & 33.5 & 5127 & 16.6 [14.8-18.6] \\
\hline Urban & 66.5 & 10,189 & $23.1[21.4-25.0]$ \\
\hline \multicolumn{4}{|l|}{ Geographic Location } \\
\hline Urban Formal & 54.1 & 8293 & 23.7 [21.7-25.9] \\
\hline Urban Informal & 12.4 & 1896 & 19.8 [16.7-23.3] \\
\hline Rural Informal (Tribal) & 21.3 & 3269 & 14 [12.2-16.0] \\
\hline Rural Formal (Farms) & 12.1 & 1858 & 25.6 [20.9-31.0] \\
\hline \multicolumn{4}{|l|}{ Province } \\
\hline Western Cape & 14.0 & 2151 & $37.9[32.9-43.2]$ \\
\hline Eastern Cape & 10.7 & 1637 & $21.6[18.4-25.1]$ \\
\hline Northern Cape & 6.5 & 995 & $33.2[25.7-41.7]$ \\
\hline Free State & 5.4 & 831 & 30.7 [26.9-34.9] \\
\hline Kwazulu Natal & 16.6 & 2547 & $20.2[17.6-23.0]$ \\
\hline North West & 12.6 & 1932 & 14.5 [12.5-16.7] \\
\hline Gauteng & 17.2 & 2631 & $15.2[12.8-18.1]$ \\
\hline Mpumalanga & 8.6 & 1324 & 17 [13.2-21.5] \\
\hline Limpopo & 8.3 & 1268 & 13.7 [10.2-18.1] \\
\hline \multicolumn{4}{|l|}{ Race } \\
\hline African & 66.9 & 10,163 & 17 [15.8-18.3] \\
\hline White & 4.7 & 718 & $25.1[20.3-30.7]$ \\
\hline Coloured & 19.8 & 3004 & $45.9[42.7-49.1]$ \\
\hline Indian & 8.5 & 1295 & 27 [21.3-33.5] \\
\hline Other & 0.1 & 8 & ISS \\
\hline \multicolumn{4}{|l|}{ Nationality } \\
\hline South African Citizen & 98.5 & 14,880 & 20.8 [19.6-22.2] \\
\hline Non - Citizen (PR) & 1.0 & 148 & 21.4 [13.2-32.9] \\
\hline Non-Citizen (Refugee) & 0.4 & 57 & $18.4[8.2-36.6]$ \\
\hline Other (Specify) & 0.1 & 16 & ISS \\
\hline \multicolumn{4}{|l|}{ Marital Status } \\
\hline Never Married & 45.3 & 5722 & $19.7[18.1-21.4]$ \\
\hline Currently Married & 44.4 & 5616 & $23.9[21.7-26.2]$ \\
\hline Formerly Married & 10.3 & 1300 & 21.4 [17.5-25.8] \\
\hline
\end{tabular}


Table 1 Distribution of respondents and the lifetime prevalence of tobacco smoking (Continued)

\begin{tabular}{|c|c|c|c|}
\hline Characteristics & $\%$ & $n=15,316$ & $\begin{array}{l}\text { Lifetime prevalence of smoking } \\
\%(95 \% \mathrm{Cl})\end{array}$ \\
\hline \multicolumn{4}{|l|}{ Employment Status } \\
\hline Unemployed & 62.2 & 7736 & $20.5[19.0-22.1]$ \\
\hline Employed & 37.8 & 4703 & $23.8[21.8-26.0]$ \\
\hline \multicolumn{4}{|l|}{ Educational Attainment } \\
\hline No formal education & 26.6 & 4003 & $24.5[22.2-27.0]$ \\
\hline Grade 8-12 & 63.6 & 9556 & 19.9 [18.4-21.5] \\
\hline Higher education & 9.8 & 1471 & 18.6 [15.3-22.3] \\
\hline \multicolumn{4}{|l|}{ Wealth Quintile } \\
\hline Lowest & 20.4 & 2625 & $21.1[18.5-23.9]$ \\
\hline Lower & 18.0 & 2309 & $17.3[15.2-19.5]$ \\
\hline Middle & 18.9 & 2423 & $19.5[17.0-22.2]$ \\
\hline Higher & 21.5 & 2764 & $23.8[20.8-27.1]$ \\
\hline Highest & 21.2 & 2719 & 20.6 [18.0-23.5] \\
\hline Total & & 15,316 & 20.5 [19.1-21.9] \\
\hline
\end{tabular}

ISS Insufficient Sample Size

(30.7\%). All other background characteristics of the respondents showed consistent lifetime smoking rates (Table 1).

A detailed analysis of ever-smoked respondents and their ages at the onset of smoking is shown in Table 2. Among the 3360 respondents who had ever smoked, the overall median age at onset of smoking was 18 years (Inter-quartile range $(I Q R)=5$ ) with $1.5 \%$ having started smoking before age 10 years. Concerning Province, $3.8 \%$ had started TS before attaining age 10 years in Limpopo compared with $0.1 \%$ in Gauteng, $74.9 \%$ started TS between ages 10 and 19 years in the Western Cape compared with $47.8 \%$ in the Free State. The median age at onset of smoking was 17 years $(\mathrm{IQR}=4)$ in the Western Cape compared with 20 years $(\mathrm{IQR}=6)$ in Free State.

Censoring the respondents who have never smoked as their current age as of the time of data collection, the survival curves of the onset of TS by selected characteristics are presented in Figs. 1 and 2. The Log-rank test for equality of survival curves showed that the curves were significantly different among the respondents' province, race location, nationality, sex, birth cohort, and wealth quintile. All the curves showed a sharp increase in the probability of uptake between the ages of 15 and 22 years. The most noticeable differences were among the provinces, location, and sex. The probabilities were consistently highest in the Western Cape, Northern Cape and Free State. It was also higher in urban areas than in rural areas, and among Africans and South African nationalities, people from households in the highest wealth quintiles, younger persons, and males.
We computed the incidence rate (IR) of TS per 10, 000 people per year in Table 3. For instance, the incidence rate of TS among all respondents was 65 per 1000. The IR was 31 among persons born aged 6 years or more, and 91 among persons aged 20 to 29 years, 120 among males and 34 among females, 79 among persons from households in higher wealth quintiles compared to those in lowest wealth quintiles. The IR was 148 among the coloured people compared to 46 among Africans, 145 in Western Cape, 115 in Northern Cape and 34 in the North West province.

The crude hazard ratio (HR) and adjusted hazard ratio of factors associated with the onset of smoking are presented in Table 3. The test of the assumption of proportionality showed that the assumptions were not violated. Hence, the Cox model was appropriate to model the data. The "hazard" or "risk" of TS was higher among younger people than older people. For instance, the hazard was $42 \%$ (adjusted Hazard Ratio $(\mathrm{aHR})=1.42$; 95\% Confidence Interval (CI):1.17-1.71) higher among people aged 20 to 29 years than those aged 60 years or more. The adjusted hazard was three times $(\mathrm{aHR}=3.37$; 95\% CI:3.08-3.68) higher among the males than the females and $29 \%$ times ( $\mathrm{aHR}=1.29 ; 95 \% \mathrm{CI}: 1.16-1.44$ ) higher among urban dwellers than rural dwellers. The hazard of TS was about three times higher in both Western Cape (aHR $=2.72$; 95\% CI:2.16-3.42) and Free State $(\mathrm{aHR}=2.42 ; 95 \% \mathrm{CI}: 3.94)$ and two times higher in Eastern Cape $(\mathrm{aHR}=2.02 ; \quad 95 \% \quad \mathrm{CI}: 1.60-2.54) \quad$ and Northern Cape $(\mathrm{aHR}=2.28 ; 95 \% \mathrm{CI}: 1.78-2.91)$ than in the North-West Province. Other significant predictors are race, employment status and household wealth quintile. 
Table 2 Distribution of age at onset of smoking and incidence rate of smoking among ever-smokers

\begin{tabular}{|c|c|c|c|c|c|c|c|}
\hline \multirow[t]{2}{*}{ Characteristics } & \multirow[t]{2}{*}{$\mathbf{n}$} & \multicolumn{6}{|c|}{ Age at Onset of Tobacco Smoking $(n=3360)$} \\
\hline & & $<10$ year & 10-19 year & 20-29 year & After 30 year & Median & IQR \\
\hline \multicolumn{8}{|l|}{ Age in years } \\
\hline$<20$ & 450 & $2[0.9-4.6]$ & $92.1[87.4-95.1]$ & $5.9[3.3-10.4]$ & $0.0[0.0-0.0]$ & 16 & 3 \\
\hline $20-29$ & 743 & $2.1[1.1-4.0]$ & $66.4[61.7-70.8]$ & $31.0[26.8-35.7]$ & $0.5[0.1-1.7]$ & 18 & 4 \\
\hline $30-39$ & 595 & $1.7[0.8-3.9]$ & $56.7[50.3-63.0]$ & $35.3[29.5-41.6]$ & $6.2[4.0-9.4]$ & 18 & 5 \\
\hline $40-49$ & 670 & $0.5[0.2-1.3]$ & $47.5[42.2-52.9]$ & $38.4[33.4-43.6]$ & $13.7[9.4-19.4]$ & 20 & 8 \\
\hline $50-59$ & 557 & $1[0.4-2.3]$ & $48.3[40.7-55.9]$ & $33.5[27.6-39.9]$ & $17.3[13.4-22.0]$ & 20 & 8 \\
\hline$>=60$ & 331 & $1.5[0.5-4.6]$ & 39.4 [29.5-50.2] & $31.9[23.8-41.4]$ & 27.2 [16.9-40.7] & 20 & 13 \\
\hline \multicolumn{8}{|l|}{ Sex } \\
\hline Males & 2218 & $1.7[1.0-2.7]$ & $59.1[56.1-62.1]$ & $33.0[30.2-35.8]$ & $6.2[5.1-7.6]$ & 18 & 5 \\
\hline Females & 1113 & $1.1[0.6-2.0]$ & $59.0[53.2-64.6]$ & $24.6[20.6-29.1]$ & 15.4 [10.8-21.4] & 18 & 6 \\
\hline \multicolumn{8}{|l|}{ Location } \\
\hline Rural & 895 & $1.9[1.1-3.5]$ & $54.7[50.0-59.3]$ & $34.2[30.1-38.6]$ & $9.2[7.2-11.6]$ & 18 & 6 \\
\hline Urban & 2451 & $1.3[0.8-2.2]$ & $60.9[57.5-64.2]$ & $29.4[26.5-32.5]$ & $8.4[6.4-11.0]$ & 18 & 5 \\
\hline \multicolumn{8}{|l|}{ Geographic Location } \\
\hline Urban Formal & 2084 & $1.3[0.7-2.3]$ & $60.9[57.0-64.6]$ & 29.5 [26.2-32.9] & $8.4[6.1-11.3]$ & 18 & 5 \\
\hline Urban Informal & 367 & $1.5[0.6-3.5]$ & $60.9[55.2-66.3]$ & $29.1[23.7-35.1]$ & $8.6[5.8-12.4]$ & 18 & 5 \\
\hline Rural Informal (Tribal) & 418 & $2.2[1.0-4.6]$ & $52.1[46.7-57.5]$ & $35.8[30.7-41.4]$ & $9.9[7.4-13.0]$ & 18 & 7 \\
\hline Rural Formal (Farms) & 477 & $1.5[0.7-3.6]$ & $59.4[50.7-67.6]$ & 31.2 [24.7-38.6] & $7.8[5.0-11.9]$ & 18 & 5 \\
\hline \multicolumn{8}{|l|}{ Province } \\
\hline Western Cape & 897 & $2.1[1.3-3.5]$ & $74.9[69.3-79.8]$ & 19 [15.6-23.0] & $3.9[2.2-6.7]$ & 17 & 4 \\
\hline Eastern Cape & 400 & $1.2[0.3-4.0]$ & $49.7[43.7-55.7]$ & $36.9[31.6-42.5]$ & $12.3[9.0-16.5]$ & 19 & 7 \\
\hline Northern Cape & 356 & $1.6[0.3-7.9]$ & $64.1[55.3-72.1]$ & $27.7[20.2-36.7]$ & $6.6[3.7-11.5]$ & 18 & 4 \\
\hline Free State & 249 & $0.9[0.2-3.9]$ & $47.8[41.0-54.7]$ & $42.8[35.1-50.8]$ & $8.5[5.5-13.0]$ & 20 & 6 \\
\hline Kwazulu Natal & 472 & $2.4[0.9-6.2]$ & $59.3[51.5-66.6]$ & $27.7[21.9-34.3]$ & $10.6[5.6-19.4]$ & 18 & 5 \\
\hline North West & 238 & $0.2[0.0-1.7]$ & $51.8[44.6-58.9]$ & $35.7[29.5-42.4]$ & $12.3[8.5-17.6]$ & 19 & 5 \\
\hline Gauteng & 380 & $0.1[0.0-0.8]$ & $55.3[48.4-62.0]$ & 35 [27.8-42.9] & $9.6[5.7-15.7]$ & 19 & 6 \\
\hline Mpumalanga & 188 & $0.4[0.1-2.5]$ & $51.3[43.3-59.3]$ & 38.9 [31.8-46.5] & $9.4[6.6-13.2]$ & 19 & 7 \\
\hline Limpopo & 166 & $3.8[1.6-8.5]$ & $54.9[43.0-66.3]$ & $33.7[24.5-44.3]$ & $7.6[4.3-13.3]$ & 18 & 7 \\
\hline \multicolumn{8}{|l|}{ Race } \\
\hline African & 1591 & $1.8[1.1-2.9]$ & $52.0[48.8-55.2]$ & $36.1[33.2-39.1]$ & $10.1[8.6-11.8]$ & 19 & 6 \\
\hline White & 177 & $0.8[0.3-2.7]$ & $65.7[53.1-76.4]$ & $21.2[13.1-32.5]$ & $12.3[4.9-27.5]$ & 18 & 4 \\
\hline Coloured & 1285 & $1.3[0.6-2.5]$ & 76.4 [72.8-79.6] & 19.8 [16.9-23.2] & $2.5[1.7-3.8]$ & 17 & 4 \\
\hline Indian & 270 & $0.3[0.1-1.4]$ & $61.1[54.0-67.8]$ & 31.9 [23.9-41.1] & $6.6[3.7-11.6]$ & 18 & 4 \\
\hline Other & 1 & ISS & ISS & ISS & ISS & ISS & ISS \\
\hline \multicolumn{8}{|l|}{ Nationality } \\
\hline South African Citizen & 3266 & $1.5[1.0-2.3]$ & 59 [56.3-61.7] & 30.8 [28.4-33.2] & $8.7[7.1-10.6]$ & 18 & 5 \\
\hline Non - Citizen (PR) & 24 & ISS & ISS & ISS & ISS & ISS & ISS \\
\hline Non-Citizen (Refugee) & 10 & ISS & ISS & ISS & ISS & ISS & ISS \\
\hline Other (Specify) & 1 & ISS & ISS & ISS & ISS & ISS & ISS \\
\hline \multicolumn{8}{|l|}{ Marital Status } \\
\hline Never Married & 1183 & $2.0[1.1-3.8]$ & $64.5[60.3-68.5]$ & $27.7[24.2-31.4]$ & $5.8[4.3-7.8]$ & 18 & 5 \\
\hline Currently Married & 1430 & $1.1[0.6-1.8]$ & 55.7 [51.3-59.9] & 32.9 [29.1-36.9] & $10.4[8.0-13.4]$ & 18 & 4 \\
\hline Formerly Married & 281 & $0.3[0.1-1.4]$ & $41.3[31.4-52.0]$ & 36.5 [27.3-46.8] & 21.9 [10.8-39.2] & 20 & 4 \\
\hline
\end{tabular}


Table 2 Distribution of age at onset of smoking and incidence rate of smoking among ever-smokers (Continued)

\begin{tabular}{|c|c|c|c|c|c|c|c|}
\hline \multirow[t]{2}{*}{ Characteristics } & \multirow[t]{2}{*}{$\mathbf{n}$} & \multicolumn{6}{|c|}{ Age at Onset of Tobacco Smoking $(n=3360)$} \\
\hline & & $<10$ year & 10-19 year & 20-29 year & After 30 year & Median & IQR \\
\hline \multicolumn{8}{|l|}{ Employment Status } \\
\hline Unemployed & 1663 & $1.6[1.0-2.8]$ & $60.2[56.6-63.7]$ & $29.6[26.4-32.9]$ & $8.6[7.1-10.4]$ & 18 & 5 \\
\hline Employed & 1214 & $1.3[0.7-2.4]$ & $57.6[53.3-61.8]$ & $33.6[29.8-37.6]$ & $7.5[5.3-10.7]$ & 18 & 6 \\
\hline \multicolumn{8}{|l|}{ Educational Attainment } \\
\hline No formal education & 896 & $1.6[0.8-3.5]$ & $49.0[44.0-54.0]$ & $33.9[29.5-38.5]$ & $15.5[12.6-18.9]$ & 19 & 8 \\
\hline Grade 8-12 & 1758 & $1.5[0.9-2.5]$ & $62.0[58.2-65.6]$ & $29.8[26.6-33.1]$ & $6.8[4.6-9.8]$ & 18 & 4 \\
\hline Higher education & 219 & $0.5[0.1-2.9]$ & $62.7[51.5-72.7]$ & $30.0[21.5-40.1]$ & $6.8[2.2-19.1]$ & 18 & 4 \\
\hline \multicolumn{8}{|l|}{ Wealth Quintile } \\
\hline Lowest & 558 & 1.3 [0.6-2.8] & $50.8[45.4-56.2]$ & 37 [31.9-42.3] & $10.9[8.1-14.6]$ & 19 & 7 \\
\hline Lower & 462 & $5.1[2.5-10.1]$ & $52.8[46.7-58.9]$ & 30.9 [25.5-36.9] & 11.2 [7.7-15.9] & 18 & 7 \\
\hline Middle & 506 & 1.6 [0.7-3.9] & $60.9[54.1-67.4]$ & $30.2[24.1-37.2]$ & $7.2[4.7-10.8]$ & 18 & 5 \\
\hline Higher & 716 & $1[0.4-2.4]$ & $61.6[55.4-67.5]$ & 31 [25.9-36.7] & $6.4[4.7-8.7]$ & 18 & 4 \\
\hline Highest & 560 & $0.6[0.3-1.6]$ & $64.8[57.0-71.9]$ & 26.9 [20.6-34.3] & 7.7 [3.2-17.3] & 18 & 4 \\
\hline Total & 3360 & 1.5 [1.0-2.2] & $59.1[56.4-61.7]$ & 30.8 [28.4-33.3] & $8.6[7.0-10.5]$ & 18 & 5 \\
\hline
\end{tabular}

ISS Insufficient Sample Size, IQR Interquartile range

\section{Discussion}

The main goal of this paper was to explore the age at the onset of tobacco smoking, as well as the determinants of the age of smoking onset using recent national data in South Africa. Results of this study confirm that one in five people in South Africa had used tobacco in their lifetime. Consistent with one of the latest data from the WHO, the average global tobacco smoking among populations aged 15 years and older was $21 \%$ [3]. The median age at onset of smoking was 18 years. This is in agreement with the reported 18.17 years among males and 18.33 years among females in South Africa by Vellios et al. [11]. Moreover, the highest lifetime prevalence of smoking was among males, those who classified themselves as "coloured" and those residing in the Western Cape. Similar rates of past-month cigarette
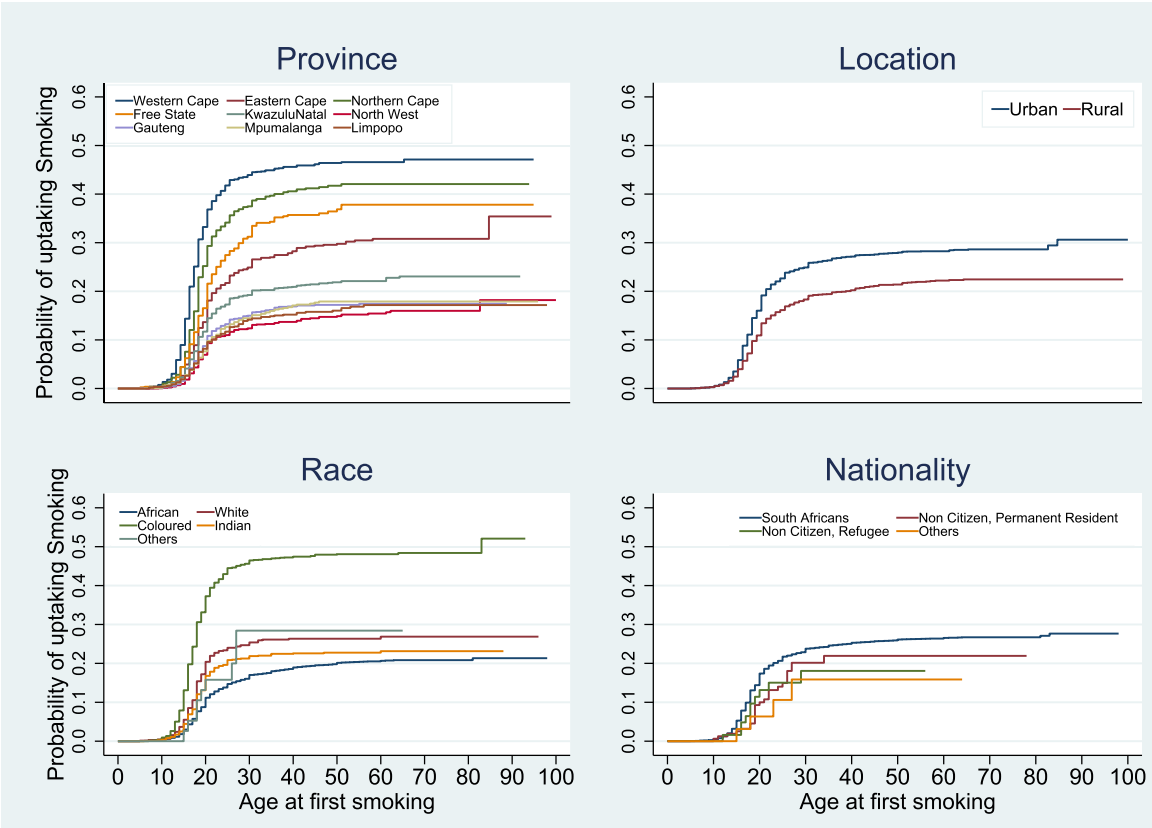

Fig. 1 Survival functions of time to onset of smoking by the race, nationality, province and location of respondents 

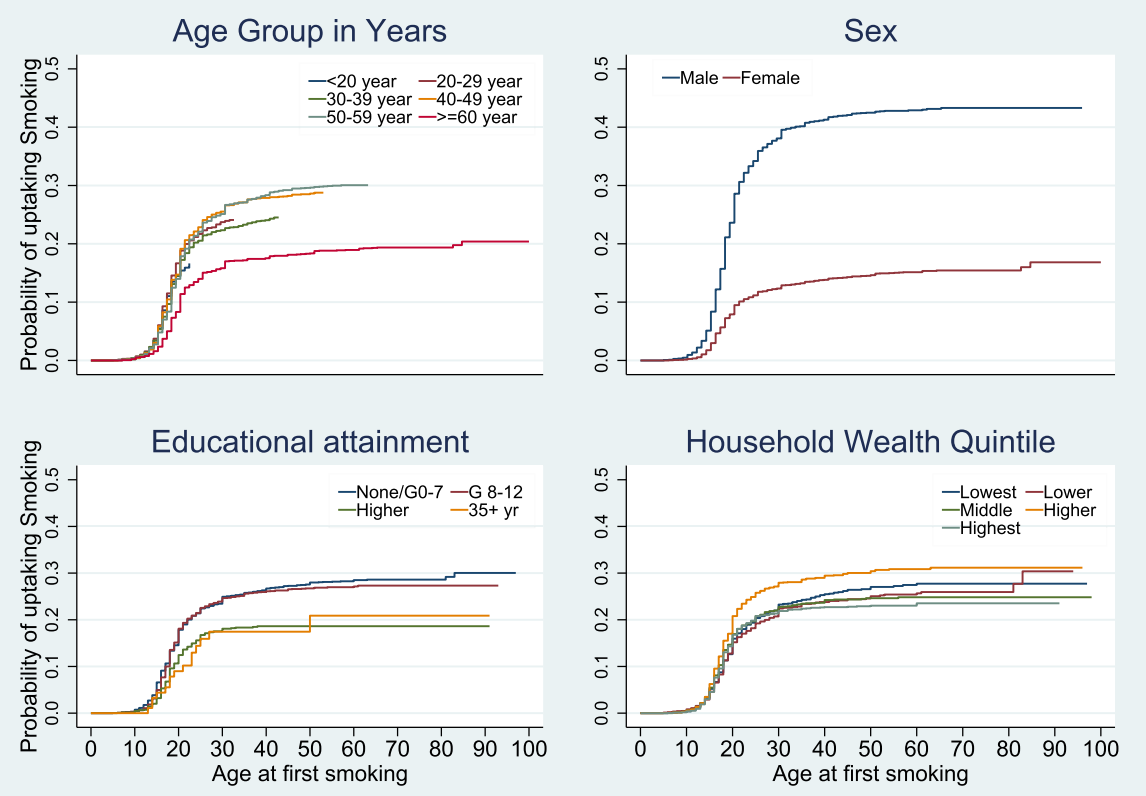

Fig. 2 Survival functions of time to onset of smoking by age, sex, educational attainment and household wealth quintile of the respondents

smoking among adult South Africans with the same demographic characteristics were found in another recent national survey [23, 24, 27]. The "coloured" people in South African have a long history of a high prevalence of smoking. In 1977, 4 of every 5 "coloured" males and half of "coloured" females were smokers [24]. Children may take to smoking because their parents and grandparents smoke, so it becomes a norm and remains prevalent over time. Smoking is seen as a way of life among the "coloured". Although the prevalence is reducing, it is generally higher among the "coloured" than what is obtainable among other races. Despite widespread knowledge of the harm caused by smoking, and concerted tobacco control efforts in the last decade [18], additional efforts, are needed to ensure continued reduction in smoking prevalence amongst the South African population.

Findings from this study show trends in smoking onset over time. Tobacco smoking started among some individuals as early as age 9 years old, and more than half of South Africans who had ever smoked initiated smoking between the ages 10-19 years. Overall, the highest risk of smoking onset usually occurred between ages 15 and 22 years across the entire population, with younger people more at risk of initiating tobacco smoking at a younger age compared to older birth cohorts. It appears that over time, people in South African have started smoking at younger ages despite substantial decreases in the prevalence of smoking in the last decades [6], these findings are worrisome. Moreover, the introduction of new tobacco products such as electronic nicotine delivery systems has the potential to also reverse the gains of decades of efforts and public health policy in South Africa, and decrease the age of smoking onset [28]. Interestingly, national studies conducted in highincome countries have shown an increase in smoking onset becoming more concentrated during young adulthood aged 18-21 years [29-32] with evidence of this found in the more recent birth cohorts [33].

This study furthermore found considerable variations in the risk of early smoking onset between sex, geographical location and the different racial groups of South Africa. The risk of early smoking onset was highest among coloured people, who comprise a high proportion of the Western Cape and Northern Cape populations. It was also higher in urban areas than in rural areas and among males compared to females. Similar findings have been reported elsewhere [2, 7, 19]. South Africa is a middle-income country with large wealth disparities, increasing proportions of the population living in urban areas and distinctive social-cultural differences [34].

\section{Strengths and limitations}

The present study is not without its limitations. The choice in the explanatory variables in this study was restricted due to the data being secondary. Respondents were also made to recall events that occurred in the past without any means of validating the responses, resulting in possible recall bias. Notwithstanding these limitations, 
Table 3 Adjusted and unadjusted determinants of timing of onset of smoking

\begin{tabular}{|c|c|c|c|c|c|}
\hline Characteristics & IR per 10,000 & $\mathrm{HR}(95 \% \mathrm{Cl})$ & $p$-value & $\operatorname{aHR}(95 \% \mathrm{Cl})$ & $p$-value \\
\hline \multicolumn{6}{|l|}{ Age in years } \\
\hline$<20$ & 70 & $1.42[1.23-1.64]^{*}$ & 0.000 & $1.27[1.03-1.57]^{*}$ & 0.027 \\
\hline $20-29$ & 91 & $1.53[1.34-1.75]^{*}$ & 0.000 & $1.42[1.17-1.71]^{*}$ & 0.000 \\
\hline $30-39$ & 72 & $1.41[1.23-1.62]^{*}$ & 0.000 & $1.27[1.05-1.53]^{*}$ & 0.012 \\
\hline $40-49$ & 72 & $1.64[1.43-1.87]^{*}$ & 0.000 & $1.43[1.20-1.71]^{*}$ & 0.000 \\
\hline $50-59$ & 64 & $1.67[1.46-1.92]^{*}$ & 0.000 & $1.46[1.22-1.74]^{*}$ & 0.000 \\
\hline$>=60$ & 31 & Reference & & & \\
\hline \multicolumn{6}{|l|}{ Sex } \\
\hline Males & 120 & $3.40[3.17-3.66]^{*}$ & 0.000 & $3.37[3.08-3.68]^{*}$ & 0.000 \\
\hline Females & 34 & Reference & & & \\
\hline \multicolumn{6}{|l|}{ Location } \\
\hline Rural & 63 & Reference & & & \\
\hline Urban & 75 & $1.40[1.30-1.51]^{*}$ & 0.000 & $1.29[1.16-1.44]^{*}$ & 0.000 \\
\hline \multicolumn{6}{|l|}{ Province } \\
\hline Western Cape & 145 & $4.27[3.70-4.93]^{*}$ & 0.000 & $2.72[2.16-3.42]^{*}$ & 0.000 \\
\hline Eastern Cape & 73 & $2.12[1.81-2.49]^{*}$ & 0.000 & $2.02[1.60-2.54]^{*}$ & 0.000 \\
\hline Northern Cape & 115 & $3.37[2.86-3.97]^{*}$ & 0.000 & $2.28[1.78-2.91]^{*}$ & 0.000 \\
\hline Free State & 96 & $2.72[2.27-3.25]^{*}$ & 0.000 & $3.09[2.42-3.94]^{*}$ & 0.000 \\
\hline Kwazulu Natal & 53 & $1.56[1.34-1.83]^{*}$ & 0.000 & $1.80[1.42-2.28]^{*}$ & 0.000 \\
\hline North West & 34 & Reference & & & \\
\hline Gauteng & 43 & $1.19[1.01-1.39]^{*}$ & 0.040 & $1.28[1.01-1.63]^{*}$ & 0.040 \\
\hline Mpumalanga & 40 & $1.16[0.96-1.41]$ & 0.122 & $1.60[1.23-2.08]^{*}$ & 0.000 \\
\hline Limpopo & 37 & $1.10[0.90-1.34]$ & 0.356 & $1.59[1.21-2.09]^{*}$ & 0.001 \\
\hline \multicolumn{6}{|l|}{ Race } \\
\hline African & 46 & Reference & & & \\
\hline White & 64 & $1.52[1.30-1.78]^{*}$ & 0.000 & $1.98[1.61-2.43]^{*}$ & 0.000 \\
\hline Coloured & 148 & $3.33[3.09-3.58]^{*}$ & 0.000 & $2.70[2.40-3.04]^{*}$ & 0.000 \\
\hline Indian & 55 & $1.27[1.12-1.45]^{*}$ & 0.000 & $1.56[1.29-1.89]^{*}$ & 0.000 \\
\hline Other & 84 & $1.49[0.77-2.86]$ & 0.235 & $1.32[0.55-3.16]$ & 0.537 \\
\hline \multicolumn{6}{|l|}{ Nationality } \\
\hline South African Citizen & 65 & $1.86[0.70-4.95]$ & 0.216 & & \\
\hline Non - Citizen (PR) & 57 & $1.40[0.49-4.00]$ & 0.530 & & \\
\hline Non-Citizen (Refugee) & 56 & $1.30[0.41-4.14]$ & 0.659 & & \\
\hline Other (Specify) & 44 & Reference & & & \\
\hline \multicolumn{6}{|l|}{ Marital Status } \\
\hline Never Married & 78 & $1.34[1.17-1.53]^{*}$ & 0.000 & $1.05[0.88-1.24]$ & 0.595 \\
\hline Currently Married & 65 & $1.29[1.13-1.46]^{*}$ & 0.000 & $0.90[0.78-1.05]$ & 0.201 \\
\hline Formerly Married & 42 & Reference & & & \\
\hline \multicolumn{6}{|l|}{ Employment Status } \\
\hline Unemployed & 64 & Reference & & & \\
\hline Employed & 76 & $1.11[1.03-1.20]^{*}$ & 0.005 & $0.86[0.78-0.94]^{*}$ & 0.001 \\
\hline \multicolumn{6}{|l|}{ Educational Attainment } \\
\hline No formal education & 61 & $1.52[1.31-1.76]^{*}$ & 0.000 & $1.02[1.01-1.03]^{*}$ & 0.000 \\
\hline Grade 8-12 & 72 & $1.47[1.28-1.69]^{*}$ & 0.000 & $1.02[1.01-1.02]^{*}$ & 0.000 \\
\hline
\end{tabular}


Table 3 Adjusted and unadjusted determinants of timing of onset of smoking (Continued)

\begin{tabular}{|c|c|c|c|c|c|}
\hline Characteristics & IR per 10,000 & $\mathrm{HR}(95 \% \mathrm{Cl})$ & $p$-value & $\operatorname{aHR}(95 \% \mathrm{Cl})$ & $p$-value \\
\hline Higher education & 48 & Reference & & & \\
\hline \multicolumn{6}{|l|}{ Wealth Quintile } \\
\hline Lowest & 66 & Reference & & & \\
\hline Lower & 60 & 0.94 [0.83-1.07] & 0.349 & 0.90 [0.79-1.03] & 0.140 \\
\hline Middle & 62 & 0.98 [0.87-1.10] & 0.691 & $0.78[0.68-0.89]^{*}$ & 0.000 \\
\hline Higher & 79 & $1.23[1.10-1.38]^{*}$ & 0.000 & $0.77[0.68-0.88]^{*}$ & 0.000 \\
\hline Highest & 79 & $0.92[0.82-1.03]$ & 0.165 & $0.54[0.46-0.63]^{*}$ & 0.000 \\
\hline Total & 65 & & & & \\
\hline
\end{tabular}

IR Incidence rate *Significant at $5 \%$

the results from this study provided a scope of the determinants of the age at smoking onset in South Africa using nationally representative data. A major strength of this study is the use of recent nationally representative data made our findings generalizable in South Africa.

\section{Conclusions}

We found that age at smoking onset in South Africa is reducing with most smokers starting at age 15-24 years. We found wide differences in the age of smoking onset concerning respondents' birth cohort, province, sex, race, wealth quintile, and employment status. The current level of age restrictions on smoking coupled with an open and electronic advertisement, including social media, of tobacco could have influenced the early onset of tobacco smoking in South Africa. The introduction of new tobacco products and electronic nicotine delivery systems might have encouraged earlier onset of smoking among youths in South Africa. There is a need for health promotion and education on the consequences of smoking starting at the primary school level. Furthermore, stricter regulations smoking advertisements and the restriction of sales of tobacco to the youth are essential.

\section{Policy implications}

Stricter regulations around advertisement of tobacco products and restricting sales of tobacco to the youth need to be implemented. Findings from high-income countries are also important to consider when implementing prevention programmes in South Africa, to avoid a generational shift in tobacco initiation in South Africa, as well as to counter the ever-evolving strategies the tobacco industry uses to market its products. The identified prognostic factors associated with the onset of tobacco smoking in South Africa show that the policy, community, organizational, interpersonal and individual levels of behaviour need to be targeted to comprehensively address smoking onset and progression, to further improve and develop smoking prevention programmes [35].

\section{Abbreviations}

aHR: Adjusted Hazard Ratio; Cl: Confidence Interval; EAs: Enumeration areas; SANHANES-1: First round of the SANHANES; HR: Hazard ratio; HSRC: Human Sciences Research Council; IR: Incidence rate; IQR: Inter-quartile range; REC: Research Ethics Committee; SES: Socioeconomic status; SANHAN ES: South African National Health and Nutrition Examination Survey;

TS: Tobacco smoking

\section{Acknowledgements}

The authors acknowledge the owners of the SANHANESS data for granting us access to the data. AFF was supported by the Consortium for Advanced Research Training in Africa (CARTA). CARTA is jointly led by the African

Population and Health Research Center and the University of the Witwatersrand and funded by the Carnegie Corporation of New York (Grant No--B 8606.R02), Sida (Grant No:54100029), and the DELTAS Africa Initiative (Grant No: 107768/Z/15/Z).

\section{Authors' contributions}

AFF conceived, designed the study, analysed the data and contributed to the first draft, RD, RS, NBK, DS and PR contributed to the study design, interpretation of results and first draft of the manuscript. All authors read and agreed to the final version of the manuscript.

\section{Funding}

The authors received no funding for this study.

\section{Availability of data and materials}

The data underlying the study are available from the Dryad repository at the following DOI: https://doi.org/10.5061/dryad.8p33r.

Ethics approval and consent to participate

The study received approval from the Research Ethics Committee (REC) of the HSRC.

(REC 6/16/11/11).

\section{Consent for publication}

Not applicable.

\section{Competing interests}

The authors declare that they have no competing interests.

\section{Author details}

'Department of Epidemiology and Medical Statistics, College of Medicine, University of Ibadan, Ibadan, Nigeria. ${ }^{2}$ Division of Population and Behavioural Sciences, School of Medicine, St Andrews University, Fife, UK. ${ }^{3}$ Division of Health Sciences, Populations, Evidence and Technologies Group, University of Warwick, Coventry, UK. ${ }^{4}$ SAMRCNits Developmental Pathways for Health Research Unit, Faculty of Health Sciences, University of the Witwatersrand, Johannesburg, South Africa. ${ }^{5}$ Health \& Wellbeing, Human and Social Capabilities Division, Human Sciences Research Council (HSRC), 116 - 118 Merchant House, Buitengracht Street, Cape Town 8001, South Africa. ${ }^{6}$ Division of Epidemiology and Biostatistics, University of the Witwatersrand, School of Public Health, Johannesburg, South Africa. ${ }^{7}$ Nelson Mandela University, Port Elizabeth, South Africa. 
Received: 25 August 2020 Accepted: 5 November 2020

Published online: 02 December 2020

\section{References}

1. $\mathrm{WHO}$. WHO global report on trends in prevalence of tobacco smoking 2000-2025. WHO: Geneva; 2018.

2. Shahwan S, Abdin E, Shafie S, Chang S, Sambasivam R, Zhang Y, et al. Prevalence and correlates of smoking and nicotine dependence: results of a nationwide cross-sectional survey among Singapore residents. BMJ Open. 2019;9 BMJ Publishing Group.

3. WHO. Global Health Observatory (GHO) Data [Internet]. Geneva; 2015. p. 29. Available from: http://www.who.int/gho/en/.

4. WHO. WHO Report on the Global Tobacco Epidemic 2011: warning about the dangers of tobacco. WHO: Geneva; 2011.

5. Moore S, Teixeira A, Stewart S. Effect of network social capital on the chances of smoking relapse: A two-year follow-up study of urban-dwelling adults. Am J Public Health. 2014;104:e72-6 American Public Health Association Inc.

6. Reddy P, Sewpaul R. Tobacco control and health [Internet]. Soc. Sci. that makes a Differ. 2014; 1-2. [cited 2020 May 30]. Available from: http://www. hsrc.ac.za/en/research-outputs/view/7016.

7. Pierce JP, White VM, Emery SL. What public health strategies are needed to reduce smoking initiation? Tob Control. 2012;21:258-64.

8. Townsend L, Flisher AJ, Gilreath T, King G. A systematic literature review of tobacco use among adults 15 years and older in sub-Saharan Africa. Drug Alcohol Depend. 2006;81(4):14-27. https://doi.org/10.1016/j.drugalcdep.2005. 12.008.

9. Peltzer K. Early sexual debut and associated factors among in-school adolescents in eight African countries. Acta Paediatr Int J Paediatr. 2010;99:1242-7.

10. Reddy P, James S, Sewpaul R, Sifunda S, Ellahebokus A, Kambaran NS, et al. Umthente Uhlaba Usamila: the 3rd South African National Youth Risk Behaviour Survey 2011 [Internet]; 2013. p. 1-26. [cited 2020 May 30]. Available from: http://www.hsrc.ac.za/en/research-data/view/6874.

11. Vellios N, Van Walbeek C. Determinants of regular smoking onset in South Africa using duration analysis. BMJ Open. 2016;6:e011076 [cited 2020 Oct 2]. Available from: http://bmjopen.bmj.com/. BMJ Publishing Group.

12. Reidpath DD, Davey TM, Kadirvelu A, Soyiri IN, Allotey P. Does one cigarette make an adolescent smoker, and is it influenced by age and age of smoking initiation? Evidence of association from the U.S. youth risk behavior surveillance system (2011). Prev Med (Baltim). 2014;59:37-41.

13. U. S. Department of Health and Human Services. Preventing tobacco use among youth and young adults: a report of the Surgeon General. DHS: Atlanta; 2012

14. Funatogawa I, Funatogawa T, Yano E. Impacts of early smoking initiation: Long-term trends of lung cancer mortality and smoking initiation from repeated cross-sectional surveys in Great Britain. BMJ Open. 2012;2:e001676 British Medical Journal Publishing Group.

15. Gore D, Kothari A. Social determinants of health in Canada: Are healthy living initiatives there yet? A policy analysis [Internet]. Int J Equity Health. 2012:41 BioMed Central. [cited 2020 May 30]. Available from: http:// equityhealthj.biomedcentral.com/articles/10.1186/1475-9276-11-41.

16. Metse AP, Wiggers J, Wye P, Moore L, Clancy R, Wolfenden L, et al. Smoking and environmental characteristics of smokers with a mental illness, and associations with quitting behaviour and motivation; A cross sectional study. BMC Public Health. 2016;16:767-78 BioMed Central Ltd.

17. Jeon KC, Goodson P. US adolescents' friendship networks and health risk behaviors: A systematic review of studies using social network analysis and Add Health data. PeerJ. 2015;3:e1052 https://doi.org/10.7717/peerj.1052.

18. Reddy P, James S, Sewpaul R, Yach D, Resnicow K, Sifunda S, et al. A decade of tobacco control: the south African case of politics, health policy, health promotion and behaviour change. S Afr Med J. 2013;103:835-40.

19. Monfared IG, Harttgen K, Vollmer S. Individual and social predictors of smoking and obesity: A panel study in Germany. SSM Popul Heal. 2020;10 Elsevier Ltd.

20. Wellman RJ, Dugas EN, Dutczak H, O'Loughlin EK, Datta GD, Lauzon B, et al. Predictors of the Onset of Cigarette Smoking: A Systematic Review of Longitudinal Population-Based Studies in Youth. Am J Prev Med. 2016; V51(5):767-78. Elsevier Inc.

21. Leonardi-Bee J, Jere ML, Britton J. Exposure to parental and sibling smoking and the risk of smoking uptake in childhood and adolescence: a systematic review and meta-analysis. Thorax. 2011;66:847-55.
22. Morojele NK, Brook JS, Brook DW. Tobacco and alcohol use among adolescents in South Africa: shared and unshared risks. J Child Adolesc Ment Health. 2016;28:139-52 Routledge. [cited 2020 Jul 26]. Available from: https://pubmed.ncbi.nlm.nih.gov/27562001/.

23. Lau YK, Tam J, Fleischer NL, Meza R. Neighbourhood deprivation, smoking, and race in South Africa: A cross-sectional analysis. Prev Med Rep. 2018;11: 202-8 Elsevier Inc.

24. Sitas F, Egger S, Bradshaw D, Groenewald P, Laubscher R, Kielkowski D, et al. Differences among the coloured, white, black, and other South African populations in smoking-attributed mortality at ages 35-74 years: A casecontrol study of 481640 deaths. Lancet. 2013;382:685-93 Elsevier. [cited 2020 Oct 2]. Available from: www.thelancet.com

25. Abiola AO, Balogun OS, Odukoya OO, Olatona FA, Odugbemi TO, Moronkola RK, et al. Age of initiation, determinants and prevalence of cigarette smoking among teenagers in Mushin local government area of Lagos state, Nigeria. Asian Pacific J Cancer Prev. 2016;17:1209-14 Asian Pacific Organization for Cancer Prevention.

26. Shisana O, Labadarios D, Rehle T, Simbayi L, Zuma K, Dhansay A, et al. South African National Health and nutrition examination survey (SANHAN ES-1). Cape Town: Human Sciences Research Council; 2014.

27. National Department of Health (NdoH), Stats SA, SAMRC, ICF. South Africa Demographic and Health Survey 2016. Pretoria, South Africa and Rockville Maryland, USA; 2019

28. Stanwick R. E-cigarettes: Are we renormalizing public smoking? Reversing five decades of tobacco control and revitalizing nicotine dependency in children and youth in Canada. Paediatr Child Health. 2015;20:101 Oxford University Press.

29. Tjora T, Hetland J, Aarø LE, Wold B, Øverland S. Late-onset smokers: how many, and associations with health behaviours and socioeconomic status. Scand J Public Health. 2012:40:537-43.

30. O'Loughlin JL, Dugas EN, O'Loughlin EK, Karp I, Sylvestre MP. Incidence and determinants of cigarette smoking initiation in young adults. J Adolesc Heal. 2014;54(1):26-32.e4. Elsevier USA. https://doi.org/10.1016/j.jadohealth. 2013.07.009

31. Kendler KS, Myers J, Damaj MI, Chen X. Early smoking onset and risk for subsequent nicotine dependence: a monozygotic co-twin control study. Am J Psychiatry. 2013;170:408-13 American Psychiatric Association.

32. Bernat $\mathrm{DH}$, Klein EG, Forster JL. Smoking initiation during young adulthood: a longitudinal study of a population-based cohort. J Adolesc Heal. 2012;51: 497-502 NIH Public Access.

33. Terry-Mcelrath YM, O'Malley PM. Trends and timing of cigarette smoking uptake among US young adults: survival analysis using annual national cohorts from 1976 to 2005. Addiction. 2015;110:1171-81 Blackwell Publishing Ltd.

34. Hurlbut WB. Overcoming poverty and inequality in South Africa: an assessment of drivers, constraints and opportunities [Internet]. Cape Town; 2018. Available from: www.worldbank.org.

35. Kothari A, Professor A, Edwards N, Yanicki S, Hansen-Ketchum P, Francis S. Socioecological Models: Strengthening Intervention Research in Tobacco Control. Drugs, Health and Society. 2007;6 (1):iii1-24.

\section{Publisher's Note}

Springer Nature remains neutral with regard to jurisdictional claims in published maps and institutional affiliations.

Ready to submit your research? Choose BMC and benefit from:

- fast, convenient online submission

- thorough peer review by experienced researchers in your field

- rapid publication on acceptance

- support for research data, including large and complex data types

- gold Open Access which fosters wider collaboration and increased citations

- maximum visibility for your research: over $100 \mathrm{M}$ website views per year

At BMC, research is always in progress.

Learn more biomedcentral.com/submission 